\title{
Adsorptive graphene doping: Effect of a polymer contaminant
}

Cite as: Appl. Phys. Lett. 110, 223104 (2017); https://doi.org/10.1063/1.4984283

Submitted: 14 February 2017. Accepted: 16 May 2017 . Published Online: 30 May 2017

William E. Arter (D), Lorenzo D'Arsié, Xingyi Wu (D), Santiago Esconjauregui, and John Robertson
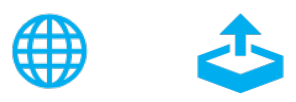

Export Citation

\section{ARTICLES YOU MAY BE INTERESTED IN}

Charge transfer doping of graphene without degrading carrier mobility

Journal of Applied Physics 121, 224304 (2017); https://doi.org/10.1063/1.4985121

Capacitance behavior of radio-frequency interdigital capacitor with single- and multi-layer graphenes

Applied Physics Letters 110, 223103 (2017); https://doi.org/10.1063/1.4984275

Optical coupling between atomically thin black phosphorus and a two dimensional photonic crystal nanocavity

Applied Physics Letters 110, 223105 (2017); https://doi.org/10.1063/1.4984597

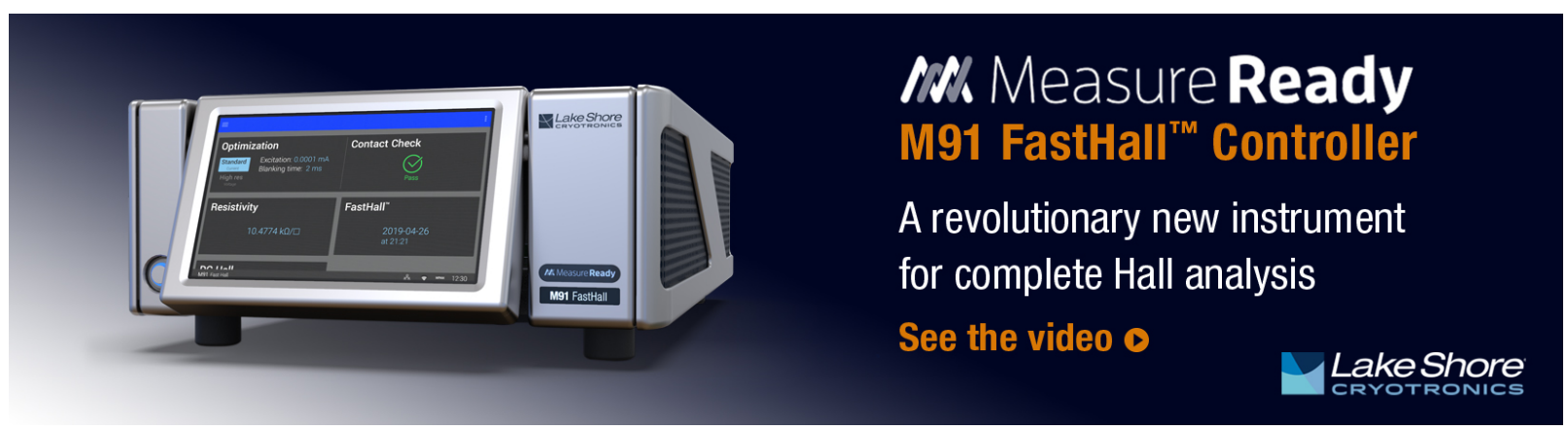




\title{
Adsorptive graphene doping: Effect of a polymer contaminant
}

\author{
William E. Arter, Lorenzo D’Arsié, ${ }^{a)}$ Xingyi Wu, Santiago Esconjauregui, \\ and John Robertson \\ Department of Engineering, University of Cambridge, Cambridge CB3 OFA, United Kingdom
}

(Received 14 February 2017; accepted 16 May 2017; published online 30 May 2017)

\begin{abstract}
Transfer-induced contamination of graphene and the limited stability of adsorptive dopants are two of the main issues faced in the practical realization of graphene-based electronics. Herein, we assess the stability of $\mathrm{HNO}_{3}, \mathrm{MoO}_{3}$, and $\mathrm{AuCl}_{3}$ dopants upon transferred graphene with different extents of polymer contamination. Sheet resistivity measurements prove that polymer residues induce a significantly degenerative effect in terms of doping stability for $\mathrm{HNO}_{3}$ and $\mathrm{MoO}_{3}$ and a highly stabilizing effect for $\mathrm{AuCl}_{3}$. Further characterization by Raman spectroscopy and atomic force microscopy (AFM) provides insight into the stability mechanism. Together, these findings demonstrate the relevance of contamination in the field of adsorptive doping for the realization of graphene-based functional devices. Published by AIP Publishing. [http://dx.doi.org/10.1063/1.4984283]
\end{abstract}

Owing to its unique mechanical, electrical, and optical properties, graphene holds much promise for application in electronics, displays, photovoltaics, and energy storage. ${ }^{1-4}$ For example, graphene has been proposed as a cheaper, flexible, and more sustainable alternative to indium tin oxide (ITO) for use in solar cells or touchscreen displays. ${ }^{5}$ One such property is the very high carrier mobility afforded by graphene's unique band structure. Despite this, however, the intrinsic carrier density of pristine graphene is very low; hence, doping is required to achieve conductivity values competitive with those of ITO thin films. This has been attempted via substitutional ${ }^{6}$ and adsorptive ${ }^{7,8}$ doping, as well as surface functionalization. ${ }^{9}$ Of these, adsorptive doping shows the most promise. The weak nature of adsorbate binding does not perturb the graphene lattice structure, thus maintaining its carrier mobility. Nevertheless, doping has been found to be unstable both over time and upon heating, limiting the practical application of graphene devices with operating temperatures in the range of $50-120{ }^{\circ} \mathrm{C} .{ }^{10}$ Given the practical necessity for stable doping, we assess how polymer contamination affects the strength and stability of $\mathrm{HNO}_{3},{ }^{11} \mathrm{MoO}_{3},{ }^{12}$ and $\mathrm{AuCl}_{3}{ }^{7}$ dopants. We find both advantageous and negative effects in terms of dopant stability and thereby contribute to the understanding of the impact of the polymer contaminant on the behavior of adsorptive dopants.

Absorptive polymer impurities commonly result from transfer of graphene during device fabrication, following synthesis via chemical vapor deposition (CVD). ${ }^{13}$ The most popular method involves a wet transfer technique by which a polymer, typically poly(methyl-methacrylate) (PMMA), is coated onto the graphene surface as a supporting layer throughout etchant removal of the deposition catalyst and subsequent transfer to the device substrate. ${ }^{14}$ Dissolution of the PMMA layer then yields, ideally, a pristine graphene surface, but a methodology that facilitates complete PMMA removal without graphene degradation has yet to be realised. ${ }^{15,16}$ This is problematic as remnant polymer residues

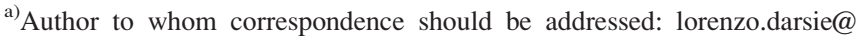
cantab.net
}

affect graphene's electronic ${ }^{17}$ and surface $^{18}$ properties. Herein, we thoroughly assess the effect of graphene contamination on dopant stability via sheet resistivity measurements and atomic force microscopy (AFM). We find that PMMA residues reduce the doping strength and facilitate degradation when $\mathrm{HNO}_{3}$ and $\mathrm{MoO}_{3}$ are employed but induce a beneficial effect for $\mathrm{AuCl}_{3}$. Following vacuum annealing at elevated temperatures, $\mathrm{AuCl}_{3}$-doped graphene is up to five times more stable than the $\mathrm{HNO}_{3}$ and $\mathrm{MoO}_{3}$ counterparts. On this basis, we observe the need to account for polymer contamination when reporting the performance of adsorptive dopants. This could have wider relevance to other fields where adsorptive doping is applied, such as in the doping of carbon nanotubes or other two dimensional materials. ${ }^{19-21}$

To obtain these results, we fabricate and measure devices using CVD-grown monolayer graphene, as previously described. ${ }^{22} \mathrm{Au} / \mathrm{Cr}(60: 6 \mathrm{~nm})$ electrodes in four-probe geometry, with inter-electrode distances of $2 / 5 / 2 \mu \mathrm{m}$, are deposited on a $\mathrm{Si} / \mathrm{SiO}_{2}$ support $\left(300 \mathrm{~nm} \mathrm{SiO}_{2}\right.$ layer). The graphene is then transferred to the $\mathrm{Si} / \mathrm{SiO}_{2}$ substrate through wet transfer with $\left(\mathrm{NH}_{4}\right)_{2} \mathrm{~S}_{2} \mathrm{O}_{8}$ etchant and a supporting PMMA thin film. Graphene strips $5 \mu \mathrm{m}$ wide are defined with oxygen plasma etch through a UVIII resist mask patterned by electron-beam lithography. Prior to doping, adventitious surface adsorbates are removed via an initial vacuum anneal. The sheet resistivity is used as a baseline for subsequent measurements. Doping is achieved by dipping the devices into $\mathrm{HNO}_{3}(68 \%$ aq.) at $50{ }^{\circ} \mathrm{C}$, by spin coating with $20 \mathrm{mM} \mathrm{AuCl}_{3}$ in $\mathrm{MeNO}_{2}$ solution, or by thermal evaporation of a $6 \mathrm{~nm} \mathrm{MoO}$ film at $\sim 10^{-6}$ mbar. These conditions optimize the doping effect for each dopant. The stability of the dopants is assessed by stepwise annealing at $70^{\circ} \mathrm{C}, 130^{\circ} \mathrm{C}$, and $200^{\circ} \mathrm{C}$ at pressures below $3 \times 10^{-6} \mathrm{mbar}$, with immediate resistivity characterization after each anneal. Currents and voltages are applied/ received by source/measurement units under ambient conditions. The maximum applied voltage is $0.06 \mathrm{~V}$ and currents are in the range of $\mu \mathrm{A}$. Sheet resistivity averages and errors are calculated from the measurement of $\geq 7$ working devices. To expel the PMMA contamination residues from the graphene surface, ${ }^{15}$ we employ two regimes: the devices are 
pre-annealed at $<3 \times 10^{-6}$ mbar at either $200^{\circ} \mathrm{C}$ for $1 \mathrm{~h}$ or $300^{\circ} \mathrm{C}$ for $2 \mathrm{~h}$. The mild pre-annealing conditions partially remove the polymer from the graphene surface, giving rise to a thickness (graphene plus contaminants) of $4.3 \pm 0.2 \mathrm{~nm}$. In contrast, the stronger conditions give rise to more thorough cleaning, resulting in graphene devices with a thickness of $0.63 \pm 0.3 \mathrm{~nm}$. This allows us to quantify the amount of PMMA per unit area (using a PMMA mass density of $1.1 \mathrm{~g}$ $\mathrm{cm}^{-3}$ ). Hence, we define heavily contaminated graphene as that exhibiting $3.73 \pm 1.5 \mu \mathrm{g} \mathrm{m}^{-2}$ and sparsely contaminated one as that with $0.63 \pm 0.15 \mu \mathrm{g} \mathrm{m}^{-2}$.

Following $\mathrm{HNO}_{3}$ or $\mathrm{MoO}_{3}$ treatment, we find that the extent of polymer contamination induces a negative effect on the doping strength [Figs. 1(a)-1(d)]. Primarily, the absolute sheet resistivity for heavily contaminated graphene appears to be consistently higher than that for the sparsely contaminated counterpart [Figs. 1(a) and 1(c)], regardless of the fact that PMMA mildly p-dopes graphene. ${ }^{17}$ Second, the doping of heavily contaminated graphene is significantly less stable than that of sparsely contaminated graphene [Figs. 1(b) and $1(\mathrm{~d})$ ]. This is quantified by plotting the average ratio of sheet resistance to as-doped sheet resistance, measured between the same devices at different annealing steps. We evidence $62 \%$ and $50 \%$ disparities in resistivity increase following annealing at $70^{\circ} \mathrm{C}$, between heavily contaminated and sparsely contaminated graphene for $\mathrm{MoO}_{3}$ and $\mathrm{HNO}_{3}$, respectively. Furthermore, the instability of heavily contaminated relative to sparsely contaminated graphene is more pronounced for $\mathrm{MoO}_{3}$ than for the $\mathrm{HNO}_{3}$ dopant. Over the annealing stages, we observe average differences of $53 \%$ and $37 \%$ in resistivity between heavily contaminated and sparsely contaminated graphene for $\mathrm{MoO}_{3}$ and $\mathrm{HNO}_{3}$, respectively. Finally, the reduced homogeneity in dopant stabilities is also evidenced by larger standard deviations in sheet resistivity ratios to as-doped graphene for heavily contaminated graphene, with a more pronounced effect for the $\mathrm{MoO}_{3}$ dopant. In this case, the average standard deviations across the annealing steps were \pm 0.22 and $\pm 0.09 \Omega / \square$ for heavily and sparsely contaminated graphene, respectively.

The effect of polymer contamination appears to be dramatically different with the $\mathrm{AuCl}_{3}$ dopant [Figs. 1(e) and 1(f)]. Following doping, we observe a remarkably low average sheet resistance of $102 \pm 4.5 \Omega / \square$ (for sparsely contaminated graphene), surpassing that observed in similar studies [Fig. 1(e)]. ${ }^{7,23,24}$ The lowest sheet resistivity observed in a single device is $85.8 \Omega / \square$. In a clear contrast to $\mathrm{HNO}_{3}$ and $\mathrm{MoO}_{3}$ dopants, the stability of the $\mathrm{AuCl}_{3}$ doping for both heavily contaminated and sparsely contaminated graphene remains practically unchanged after annealing at $70^{\circ} \mathrm{C}$ and $130^{\circ} \mathrm{C}$. After annealing at $200^{\circ} \mathrm{C}$, however, the heavily contaminated graphene samples exhibit greater dopant stability than that on sparsely contaminated graphene [Fig. 1(f)].

These results are also reflected by Raman characterization $(514 \mathrm{~nm}$ laser at $\sim 500 \mu \mathrm{W}$ with a $50 \times$ objective and a spot diameter of $\sim 1.5 \mu \mathrm{m}$ ) of heavily contaminated graphene before and after doping with all dopants and subsequent annealing at $200^{\circ} \mathrm{C}$ (Fig. 2). The un-doped graphene spectrum has an $\mathrm{I}_{2 \mathrm{D}} / \mathrm{I}_{\mathrm{G}}$ ratio of $\sim 2.3$, a $\mathrm{G}$ peak full-width at half maximum of $\sim 30 \mathrm{~cm}^{-1}$, and a negligible D peak, concurrent with high quality, monolayer graphene. ${ }^{25}$ The presence of an additional shoulder at slightly lower wavenumber than the $G$ peak is assigned to carbon contamination of the graphene layer. The fact this is absent in the spectra for $\mathrm{HNO}_{3}$ and $\mathrm{AuCl}_{3}$ dopants suggests that the doping process also induces removal of some contaminants from graphene. ${ }^{26,27}$ This is confirmed by its presence in the spectra for the $\mathrm{MoO}_{3}$ dopant

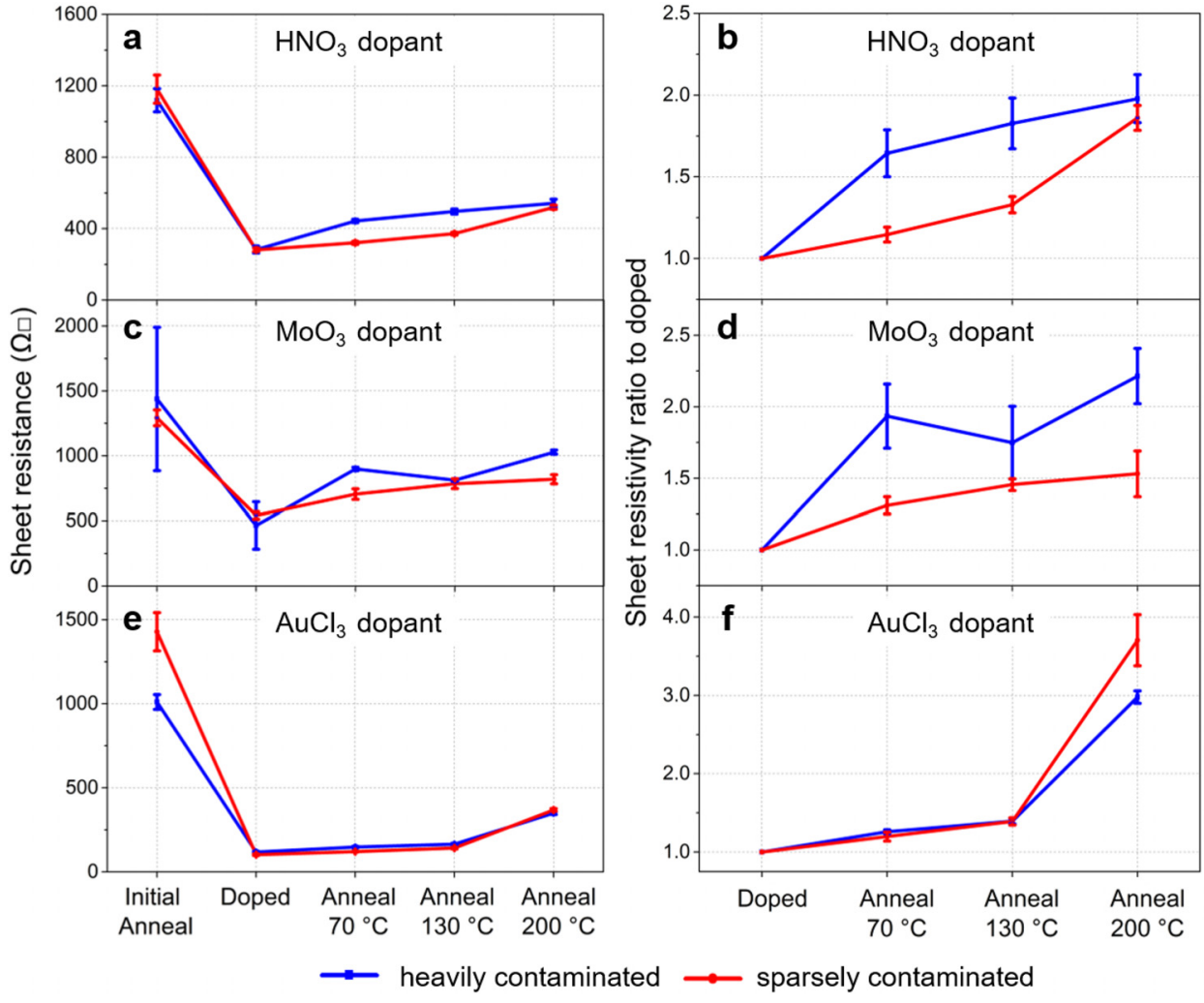

FIG. 1. Sheet resistivity of heavily and sparsely contaminated graphene following initial anneal, doping, and annealing at $70^{\circ} \mathrm{C}, 130^{\circ} \mathrm{C}$, and $200^{\circ} \mathrm{C}$ for (a) $\mathrm{HNO}_{3}$, (c) $\mathrm{MoO}_{3}$, and (e) $\mathrm{AuCl}_{3}$. Ratios of sheet resistance following annealing for heavily and sparsely contaminated graphene relative to that of as-doped graphene for (b) $\mathrm{HNO}_{3}$, (d) $\mathrm{MoO}_{3}$, and (f) $\mathrm{AuCl}_{3}$. 


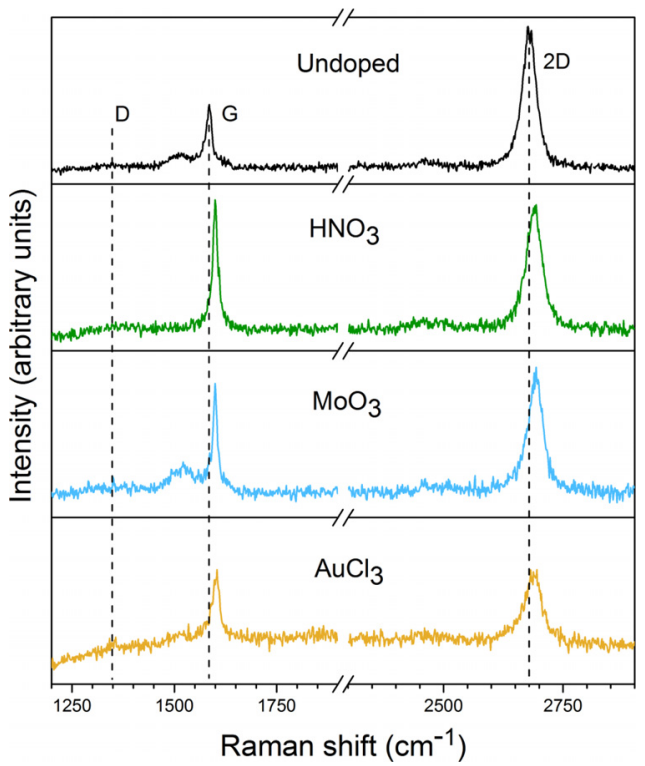

FIG. 2. Raman spectrum of as-transferred heavily contaminated graphene, and spectra following doping by $\mathrm{HNO}_{3}, \mathrm{MoO}_{3}$, and $\mathrm{AuCl}_{3}$ and annealing at $200^{\circ} \mathrm{C}$. (as we use oxide evaporation) and helps explain the highly unstable $\mathrm{MoO}_{3}$ doping observed. Additionally, the absence of a notable D peak in the doped spectra indicates that the doping and annealing processes do not induce defects on the graphene sheets. ${ }^{23,26,27}$ A shift to higher wavenumber in the $G$ and $2 \mathrm{D}$ peaks is observed for the doped graphene spectra, alongside a variation in relative $2 \mathrm{D} / \mathrm{G}$ intensities to $\mathrm{I}_{2 \mathrm{D}} / \mathrm{I}_{\mathrm{G}} \sim 1$. These changes are indicative of the doping effect induced by all three of the dopants investigated. ${ }^{28}$

To rationalize these observations, we conducted further analysis via AFM [Figs. 3(a)-3(f)]. We find that after $\mathrm{HNO}_{3}$ doping and annealing, the heavily contaminated graphene samples are decorated with large features which we attribute to polymer agglomeration [Fig. 3(c)]. In contrast, sparsely contaminated graphene appeared nearly unchanged from the pre-doped form [Fig. 3(d)]. These results evidence that large quantities of PMMA in close contact to the graphene surface display the greatest resilience to displacement by chemical or thermal means, as suggested previously. ${ }^{15}$ We compare these findings to those of previous studies in our laboratory and elsewhere 26,27,29 concerning $\mathrm{MoO}_{3}$ and $\mathrm{HNO}_{3}$ dopants on pristine graphene, which report markedly smaller doping instability.
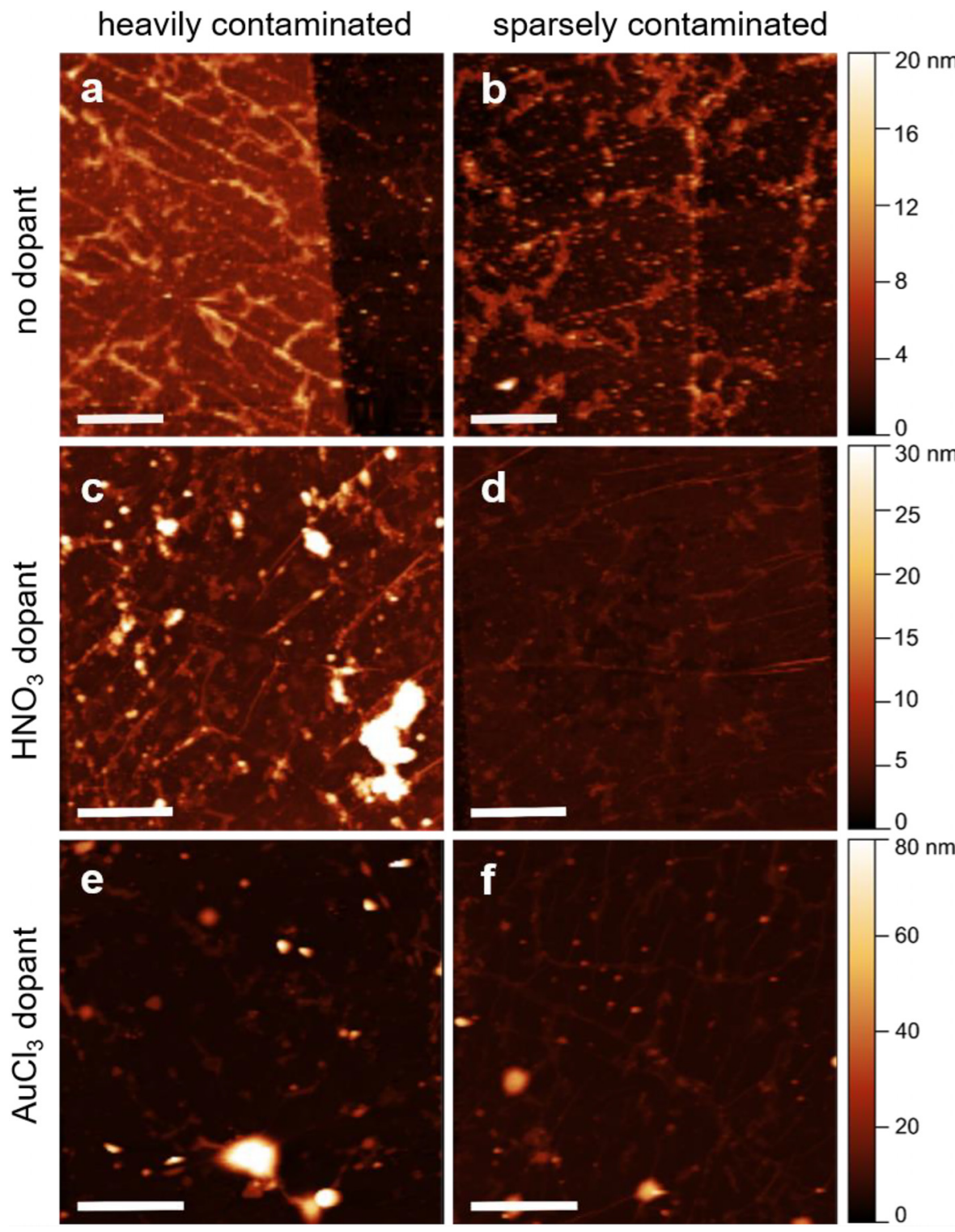

FIG. 3. AFM micrographs of (a) heavily and (b) sparsely contaminated graphene before doping, and following doping by $\mathrm{HNO}_{3}$ and $\mathrm{AuCl}_{3}$ and annealing at $200^{\circ} \mathrm{C}$, (c), (d) and (e), (f), respectively. Lateral scale bar $=1 \mu \mathrm{m}$. 
In those accounts, $\mathrm{MoO}_{3}$ was found to be completely stable, ${ }^{27}$ and $\mathrm{HNO}_{3}$ exhibited only a $2 \%$ increase in resistivity following annealing at $130^{\circ} \mathrm{C}^{26}$ Therefore, we resolve that polymer contamination has a significant, negative effect on the stability of $\mathrm{MoO}_{3}$ and $\mathrm{HNO}_{3}$ dopants.

For the $\mathrm{AuCl}_{3}$ case [Figs. 3(e) and 3(f)], we find that the samples are decorated with Au nanoparticles (AuNP) which have formed upon reduction of $\mathrm{Au}$ (III) species on the graphene surface and melted and agglomerated into larger clusters upon annealing. ${ }^{24,30}$ The number density of nanoparticles is $5.3 \pm 0.5 \mu \mathrm{m}^{-2}$ for heavily contaminated graphene and $3.2 \pm 0.2 \mu \mathrm{m}^{-2}$ for the sparsely contaminated samples. The particle size (measured above a $15 \mathrm{~nm}$ height threshold to account for particles of polymer residue) averages $63 \pm 2$ and $80 \pm 3 \mathrm{~nm}$, respectively. Such assessment is possible as agglomerated Au clusters and polymer residues appear to have different features upon AFM characterization. While Au nanoparticles are fairly spherical, polymer residues are rather irregular and amorphous. On this basis, we hypothesize that on average, smaller AuNPs are formed on heavily contaminated graphene as the residues limit Au surface diffusion, in agreement with previous observations. ${ }^{31-34} \mathrm{We}$ note that in addition to purely metallic $\mathrm{Au}$ on the graphene surface, $\mathrm{AuCl}_{4}{ }^{-}$and $\mathrm{Cl}$-containing species are also present in the doping process. ${ }^{24}$ Charge-transfer equilibrium between electrondeficient graphene and $\mathrm{Cl}^{-}$produces $\mathrm{Cl}$ species, which adsorb to the surface and play a key role in maintaining the doping effect: temperature-induced desorption of $\mathrm{Cl}_{2}$ results in increased sheet resistivity. ${ }^{23,24}$ In light of the differential AuNP agglomeration, we attribute the stabilizing behavior of the polymer contaminant to reduced surface diffusion of dopant species across the graphene. Such stabilization retards the formation and desorption of $\mathrm{Cl}_{2}$ and thus slows any increases in resistivity during annealing. Figure 4 cartoons the possible scenarios for absorptive doping on polymer-contaminated graphene.

This work exemplifies the extent to which polymer residues present a challenge to the control of adsorptively doped polymer-transferred CVD graphene. Furthermore, the mechanism by which contamination affects dopant stability is not generic and depends upon the nature of the dopant employed. However, we would expect to observe similar, destabilising, behaviour as in the $\mathrm{MoO}_{3}$ case for other vapour-deposited,

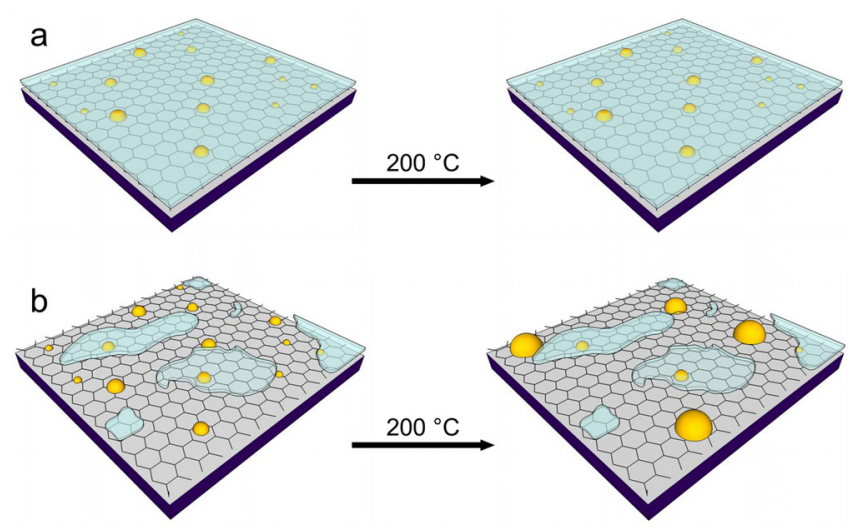

FIG. 4. Cartoon showing variation in AuNP growth, dependent on the extent of polymer contamination for (a) heavily contaminated and (b) sparsely contaminated graphene. adlayer dopants such as $\mathrm{WO}_{3}$, due to analogous degradation of the dopant/graphene interface. Whilst dopant behaviour is difficult to predict, we believe that polymer contamination can be expected to modify the properties of other p-type dopants such as $\mathrm{I}_{2}$ and indeed adsorptive n-type dopants also. ${ }^{35,36}$

In summary, we have explored the effect of a polymer contaminant on the strength and stability of adsorptive graphene dopants. The quantity of contaminating PMMA residue on graphene has been found to negatively affect the stability of $\mathrm{HNO}_{3}$ and $\mathrm{MoO}_{3}$-doped graphene at elevated temperatures, with this response most pronounced for $\mathrm{MoO}_{3}$. Conversely, when doped with $\mathrm{AuCl}_{3}$, a stabilising effect is recorded at high temperatures in the presence of heavier polymer contamination. These findings are significant to the production and accurate characterisation of stable, adsorptively doped graphene.

W.E.A. acknowledges support from the EPSRC Cambridge NanoDTC, EP/L015978/1. L.D. acknowledges funding from EPSRC. X.W. acknowledges a scholarship from the Cambridge Overseas Trust and Learning and Research Funding from St John's College Cambridge.

${ }^{1}$ M. F. El-Kady and R. B. Kaner, ACS Nano 8, 8725-8729 (2014).

${ }^{2}$ S. Bae, H. Kim, Y. Lee, X. Xu, J.-S. Park, Y. Zheng, J. Balakrishnan, T. Lei, H. R. Kim, Y. Il Song et al., Nat. Nanotechnol. 5, 574-578 (2010).

${ }^{3}$ C.-T. Chien, P. Hiralal, D.-Y. Wang, I.-S. Huang, C.-C. Chen, C.-W. Chen, and G. A. J. Amaratunga, Small 11, 2929-2937 (2015).

${ }^{4}$ L. Kavan, J.-H. Yum, and M. Grätzel, Nano Lett. 11, 5501-5506 (2011).

${ }^{5}$ G. Jo, M. Choe, S. Lee, W. Park, Y. H. Kahng, and T. Lee, Nanotechnology 23, 112001 (2012).

${ }^{6}$ D. Wei, Y. Liu, Y. Wang, H. Zhang, L. Huang, and G. Yu, Nano Lett. 9, 1752-1758 (2009).

${ }^{7}$ K. C. Kwon, B. J. Kim, J.-L. Lee, and S. Y. Kim, J. Mater. Chem. C 1, 2463-2469 (2013).

${ }^{8}$ T. O. Wehling, K. S. Novoselov, S. V. Morozov, E. E. Vdovin, M. I. Katsnelson, A. K. Geim, and A. I. Lichtenstein, Nano Lett. 8, 173-177 (2008).

${ }^{9}$ A. Sinitskii, A. Dimiev, D. A. Corley, A. A. Fursina, D. V. Kosynkin, and J. M. Tour, ACS Nano 4, 1949-1954 (2010).

${ }^{10}$ H. A. Koffi, V. C. K. Kakane, A. Kuditcher, A. F. Hughes, M. B. Adeleye, and J. K. Amuzu, Afr. J. Sci. Technol. Innovation Dev. 7, 485-490 (2015).

${ }^{11}$ H.-J. Lee, E. Kim, J. Park, W. Song, K.-S. An, Y. S. Kim, J.-G. Yook, and J. Jung, Carbon 78, 532-539 (2014).

${ }^{12}$ P. R. Kidambi, C. Weijtens, J. Robertson, S. Hofmann, and J. Meyer, Appl. Phys. Lett. 106, 63304 (2015).

${ }^{13}$ R. Muñoz and C. Gómez-Aleixandre, Chem. Vap. Deposition 19, 297-322 (2013).

${ }^{14}$ X. Li, W. Cai, J. An, S. Kim, J. Nah, D. Yang, R. Piner, A. Velamakanni, I. Jung, E. Tutuc et al., Sci. 324, 1312-1314 (2009).

${ }^{15}$ Y. C. Lin, C. C. Lu, C. H. Yeh, C. Jin, K. Suenaga, and P. W. Chiu, Nano Lett. 12, 414-419 (2012).

${ }^{16}$ X. Liang, B. A. Sperling, I. Calizo, G. Cheng, C. A. Hacker, Q. Zhang, Y. Obeng, K. Yan, H. Peng, Q. Li et al., ACS Nano 5, 9144-9153 (2011).

${ }^{17}$ A. Pirkle, J. Chan, A. Venugopal, D. Hinojos, C. W. Magnuson, S. McDonnell, L. Colombo, E. M. Vogel, R. S. Ruoff, and R. M. Wallace, Appl. Phys. Lett. 99, 122108 (2011).

${ }^{18}$ M. Kratzer, B. C. Bayer, P. R. Kidambi, A. Matković, R. Gajić, A. Cabrero-Vilatela, R. S. Weatherup, S. Hofmann, and C. Teichert, Appl. Phys. Lett. 106, 103101 (2015).

${ }^{19}$ R. Graupner, J. Abraham, A. Vencelová, T. Seyller, F. Hennrich, M. M. Kappes, A. Hirsch, and L. Ley, Phys. Chem. Chem. Phys. 5, 5472-5476 (2003).

${ }^{20}$ K. K. Kim, J. J. Bae, H. K. Park, S. M. Kim, H.-Z. Geng, K. A. Park, H.-J. Shin, S.-M. Yoon, A. Benayad, J.-Y. Choi et al., J. Am. Chem. Soc. 130, 12757-12761 (2008).

${ }^{21}$ S. Esconjauregui, L. D’Arsié, Y. Guo, J. Yang, H. Sugime, S. Caneva, C. Cepek, and J. Robertson, ACS Nano 9, 10422-10430 (2015). 
${ }^{22}$ X. Wu, G. Zhong, L. D'Arsié, H. Sugime, S. Esconjauregui, A. W. Robertson, and J. Robertson, Sci. Rep. 6, 21152 (2016).

${ }^{23}$ K. W. Kim, W. Song, M. W. Jung, M.-A. Kang, S. Y. Kwon, S. Myung, J. Lim, S. S. Lee, and K.-S. An, Carbon 82, 96-102 (2015).

${ }^{24}$ D. Hee Shin, J. Min Kim, C. Wook Jang, J. Hwan Kim, S. Kim, and S. H. Choi, J. Appl. Phys. 113, 064305 (2013).

${ }^{25}$ Y. Ying Wang, Z. Hua Ni, T. Yu, Z. X. Shen, H. Min Wang, Y. Hong Wu, W. Chen, and A. T. Shen Wee, J. Phys. Chem. C 112, 10637-10640 (2008).

${ }^{26}$ L. D'Arsié, S. Esconjauregui, R. S. Weatherup, X. Wu, W. E. Arter, H. Sugime, C. Cepek, and J. Robertson, RSC Adv. 6, 113185-113192 (2016).

${ }^{27}$ L. D'Arsié, S. Esconjauregui, R. Weatherup, Y. Guo, S. Bhardwaj, A. Centeno, A. Zurutuza, C. Cepek, and J. Robertson, Appl. Phys. Lett. 105, 103103 (2014).

${ }^{28}$ A. Das, S. Pisana, B. Chakraborty, S. Piscanec, S. K. Saha, U. V. Waghmare, K. S. Novoselov, H. R. Krishnamurthy, A. K. Geim, A. C. Ferrari et al., Nat. Nanotechnol. 3, 210-215 (2008).
${ }^{29}$ Z. Chen, I. Santoso, R. Wang, L. F. Xie, H. Y. Mao, H. Huang, Y. Z. Wang, X. Y. Gao, Z. K. Chen, D. Ma et al., Appl. Phys. Lett. 96, 213104 (2010).

${ }^{30}$ R. A. Nistor, D. M. Newns, and G. J. Martyna, ACS Nano 5, 3096-3103 (2011).

${ }^{31}$ L. Meli and P. F. Green, ACS Nano 2, 1305-1312 (2008).

${ }^{32}$ R. Popescu, R. Schneider, D. Gerthsen, A. Böttcher, D. Löffler, P. Weis, and M. M. Kappes, Surf. Sci. 603, 3119-3125 (2009).

${ }^{33}$ M. Watanabe, T. Akimoto, and E. Kondoh, Phys. Status Solidi A 209, 2514-2520 (2012).

${ }^{34}$ S. B. Simonsen, I. Chorkendorff, S. Dahl, M. Skoglundh, J. Sehested, and S. Helveg, J. Catal. 281, 147-155 (2011).

${ }^{35}$ B. H. Kim, S. J. Hong, S. J. Baek, H. Y. Jeong, N. Park, M. Lee, S. W. Lee, M. Park, S. W. Chu, H. S. Shin et al., Sci. Rep. 2, 690 (2012).

${ }^{36}$ I. Jo, Y. Kim, J. Moon, S. Park, J. S. Moon, W. B. Park, J. S. Lee, B. H. Hong, K. S. Novoselov, A. K. Geim et al., Phys. Chem. Chem. Phys. 17, 29492-29495 (2015). 